\title{
A STOCHASTIC MODEL FOR CRACK INITIATION LIFE PREDICTION OF AN AUSTENITIC STAINLESS STEEL UNDER CONSTANT AMPLITUDE LOADING
}

\author{
R. Yahiaoui ${ }^{1 *}$, R. Noureddine ${ }^{1}$, B. Ait Saadi ${ }^{2}$ \\ ${ }^{1}$ Institute of Maintenance and Industrial Safety, University of Oran 2 Mohamed Ben Ahmed, \\ Oran, Algeria \\ e-mail: yahiaoui.reda@univ-oran2.dz \\ ${ }^{2}$ Department of Physics, University of Science and Technology of Oran Mohamed Boudiaf, \\ Oran, Algeria \\ *corresponding author
}

\begin{abstract}
Predicting crack initiation life (CIL) of a mechanical component or a structure in service remains difficult since the crack formation process is of stochastic nature. To ensure a high level of safety and reliability, it is essential to have an appropriate probability distribution law of the CIL to ensure that cracks can be detected before reaching a critical length. In the present study, a stochastic model is used to predict the number of cycles corresponding to the formation of a crack $500 \mu \mathrm{m}$ long resulted from the nucleation, growth, and coalescence of multiple microcracks. The model is applied in the case of a $316 \mathrm{~L}$ austenitic stainless steel for different plastic strain ranges.
\end{abstract}

Keywords: Microcrack density, Coalescence, Crack initiation, 316L

\section{Introduction}

Most of mechanical components and structures undergoing a cyclic loading are concerned with fatigue damage, where cracks can initiate and propagate even in the absence of defects or stress concentration zones. The process of fatigue damage consists generally of a crack initiation stage followed by crack propagation. The duration of each stage depends globally on the nature of the material and the operating conditions. Hence, crack initiation can occupy a significant part of the fatigue lifetime (Zhixue 2001, Provan et al. 1991), where microcracks nucleate and develop collectively in the so-called short crack regime to form the dominant crack (Qiao et al. 2005). The growth of such cracks is largely affected by the material microstructure (Miller 1987, Plumtree et al. 1991, Lukáš et al. 2003), and a good comprehension of the mechanisms governing their development is crucial to predict the formation of the dominant crack (Golden et al. 2019).

From the engineering point of view, it is essential to apply an appropriate probability distribution law of the CIL to detect the crack at an early stage and to reduce the inspection effort. The development of models that can predict the CIL as accurately as possible is of great interest. A stochastic model is presented in this study to deal with such a problem, where the number of cycles corresponding to the formation of the dominant crack is computed. The model is applied, for different plastic strain ranges $\left(\Delta \varepsilon_{p}\right)$, in the case of a $316 \mathrm{~L}$ austenitic stainless steel. 


\section{Model presentation}

During the early stage of fatigue, the damage is supposed to be localized globally at the surface material as suggested by many authors (Bataille et al. 1994, Carstensen et al. 2001, VarvaniFarahani et al. 1996). Consequently, the nucleated microcracks can be regarded as surface defects and an analysis in two dimensions can be sufficient to describe their subsequent development. The cracking process is performed until the formation of a crack $500 \mu \mathrm{m}$ long, which is considered as the dominant crack leading to failure (Brechet et al. 1992). The developed model, of Monte Carlo type, is based on a probabilistic approach concerning microcracks nucleation and growth treatment to consider the stochastic nature of the material microstructure and the intermittent growth of microcracks.

\subsection{Microcrack nucleation}

The surface material is represented by an artificial microstructure obtained from a Voronoi tessellation, which is largely used in material science (Bertolino et al. 2007). Microcrack nucleation process continues during the whole phase preceding the formation of the dominant crack while considering the stress relaxation zones, which are formed around the existing microcracks and referred to as the shielded zones (Ignatovich et al. 2005). As the density of microcracks increases, the shielded zones increase in turn and reduce the probable sites of microcrack initiation, making the nucleation of new microcracks more and more difficult. To consider this effect, the nucleation process is described by a law based on the two-parameter Weibull law:

$$
F(N)=D_{\max }\left(1-\exp \left[-\left(\frac{N}{\alpha}\right)^{\beta}\right]\right)
$$

Where, $N$ : the number of cycles, $D_{\max }$ : the maximum microcrack density, $\alpha$ and $\beta$ : the scale and shape parameters respectively.

$$
\text { Let } c=\left(\frac{1}{\alpha}\right)^{\beta} \text {, then: }
$$

$$
F(N)=D_{\max }\left(1-\exp \left[-c(N)^{\beta}\right]\right)
$$

The values of $c$ and $\beta$ are obtained from the microcrack densities presented for different plastic strain ranges (Bataille et al. 1994, Magnin et al. 1989), and are expressed as:

$$
\begin{gathered}
\beta=0.76+0.59 \exp \left(-223.04 \Delta \varepsilon_{p}\right) \\
c=0.11+0.1 \exp \left(-76.29 \Delta \varepsilon_{p}\right)
\end{gathered}
$$

The grains of the material are randomly selected for microcrack nucleation, and the initiation site is taken as the center of the grain. However, if this site is located in any shielded zone, which is considered as the circular area surrounding the microcrack (Malésys et al. 2009, Zhu et al. 2018), the grain is discarded from the selection and another grain is chosen instead.

\subsection{Microcrack growth}

To consider the stochastic nature of the material, a random orientation is affected to each grain that determines the most favorable slip system for microcrack nucleation and its subsequent 
growth. However, the intermittent growth observed for microcracks is treated by a probabilistic approach and is controlled by a propagation threshold (PT). For each microcrack growth treatment, a random variable is generated according to a uniform law and will be compared to the value of PT. If the generated variable is higher than PT, the microcrack will advance, otherwise, it will remain in an arrest mode until the next treatment. The value of PT is obtained, as suggested by Bataille et al. (1994), by adjusting the simulated results to the experimental data for the two plastic strain ranges.

\subsection{Coalescence criterion}

As the microcrack density increases, the coalescence phenomenon intervenes and affects considerably their development. A dominant crack can be formed from the coalescence of many microcracks (Vašek et al. 1991, Xu et al. 2018). This phenomenon is mainly controlled by the geometric disposition of the microcracks and the size of the interaction zone developed at their tips, which is widely admitted as the plastic zones (Jiŝa et al. 2010). Before each microcrack advancement, a coalescence test is carried out and two microcracks are considered in coalescence when their plastic zones overlap. In the case of a semicircular surface crack, the plastic zone radius $\left(r_{p}\right)$ is defined by Lankford (1985) as:

$$
r_{p}=0.15\left(1.32 \sigma_{\max } \frac{\sqrt{a}}{\sigma_{y}}\right)^{2}
$$

Where, $a$ : half the surface crack length, $\sigma_{\max }$ : maximum applied stress, $\sigma_{y}$ : yielding stress of the material.

\subsection{Number of cycles calculation}

Depending on the microcrack length, the number of cycles $(\Delta N)$ corresponding to each elementary advancement $(\Delta L)$ of the microcrack is calculated according to the given crack growth rate in the case of the $316 \mathrm{~L}$ austenitic stainless steel (Bataille et al. 1994):

$$
\begin{gathered}
0<L \leq d: \quad \Delta N=\frac{\Delta L}{2.10^{-5}\left(\Delta \varepsilon_{p}\right)^{1.36}} \\
d<L \leq 3 d: \quad \Delta N=\frac{\Delta L}{5.10^{-4}\left(\Delta \varepsilon_{p}\right)^{1.9}} \\
L>3 d: \quad \Delta N=\frac{\Delta L}{0.33\left(\Delta \varepsilon_{p}\right)^{1.33} L}
\end{gathered}
$$

Where, $L$ : crack length, d: mean grain size ( $d=50 \mu \mathrm{m}$ for $316 \mathrm{~L}$ (Brechet et al. 1992))

An average number of cycles is calculated then after over all propagated microcracks, and the total number of cycles is written as:

$$
N_{i+1}=N_{i}+\frac{\sum_{i=1}^{n} \Delta N_{i}}{n}
$$

Where, $N_{i}$ : prior number of cycles, $n:$ number of propagated microcracks. 


\section{Results and discussion}

The application of the model, for different plastic strain ranges, provides a description of the damage evolution and an estimate of the number of cycles corresponding to the formation of the dominant crack. A typical microcracks distribution is presented for $\Delta \varepsilon_{p}=8.10^{-4}$ (Fig. 1). The microcracks evolution illustrates the effect of the grain boundaries on the cracking process, where several microcracks remain blocked at these barriers, while the rest develop individually or through the coalescence phenomenon. This is in good accordance with the experimental observations reported by several authors (Hong et al. 2002, Deng et al. 2015, Gall et al. 2005).

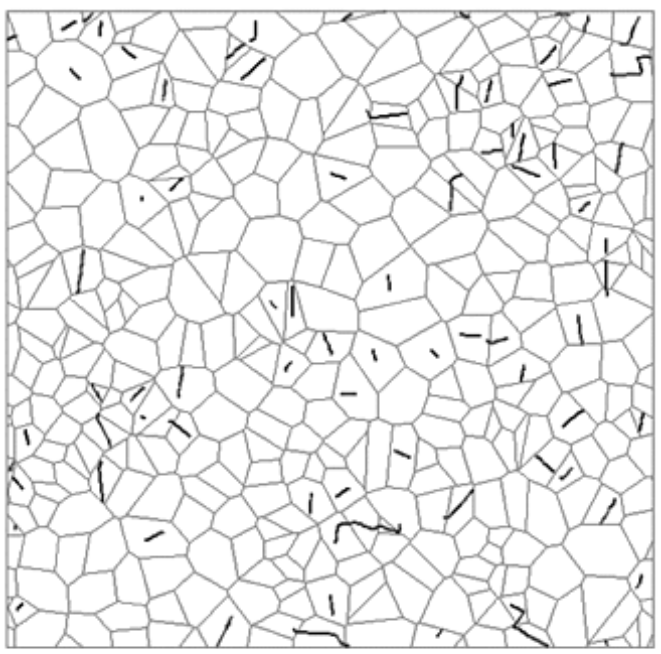

(a)

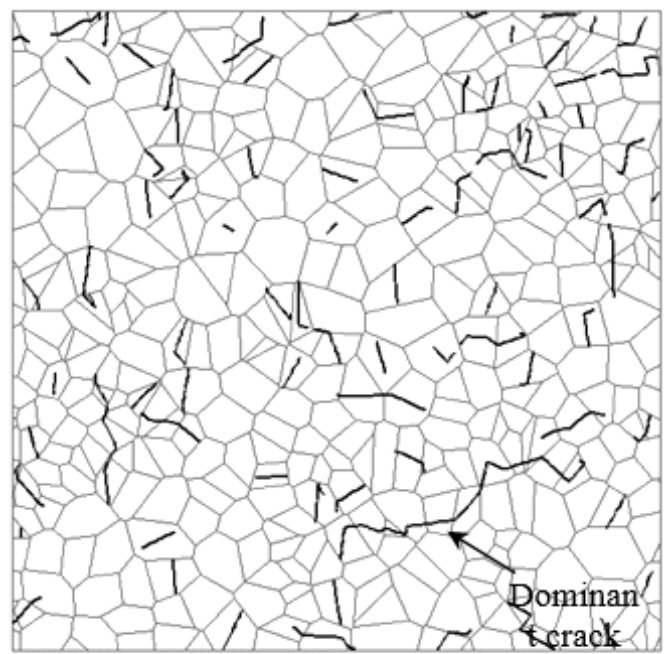

(b)

Figure 1. Simulated microcracks distribution for $\Delta \varepsilon_{p}=8 \cdot 10^{-4}$. (a) $\mathrm{N}=120000$ cycles; (b) $\mathrm{N}=$ 290000 cycles

Microcrack density is calculated during the cracking process and shows a reasonable agreement with the total microcrack densities obtained from the experimental data (Bataille et al. 1994, Magnin et al. 1989) as shown in Fig. 2, where $\mathrm{N}_{\text {init }}$ corresponds to the number of cycles to form the dominant crack. The observed fall in microcrack density is attributed to the coalescence effect that becomes more intense with the increase in microcrack density (Mazánová et al. 2018), and to the microcrack nucleation that becomes more difficult with the development of the shielded zones. 

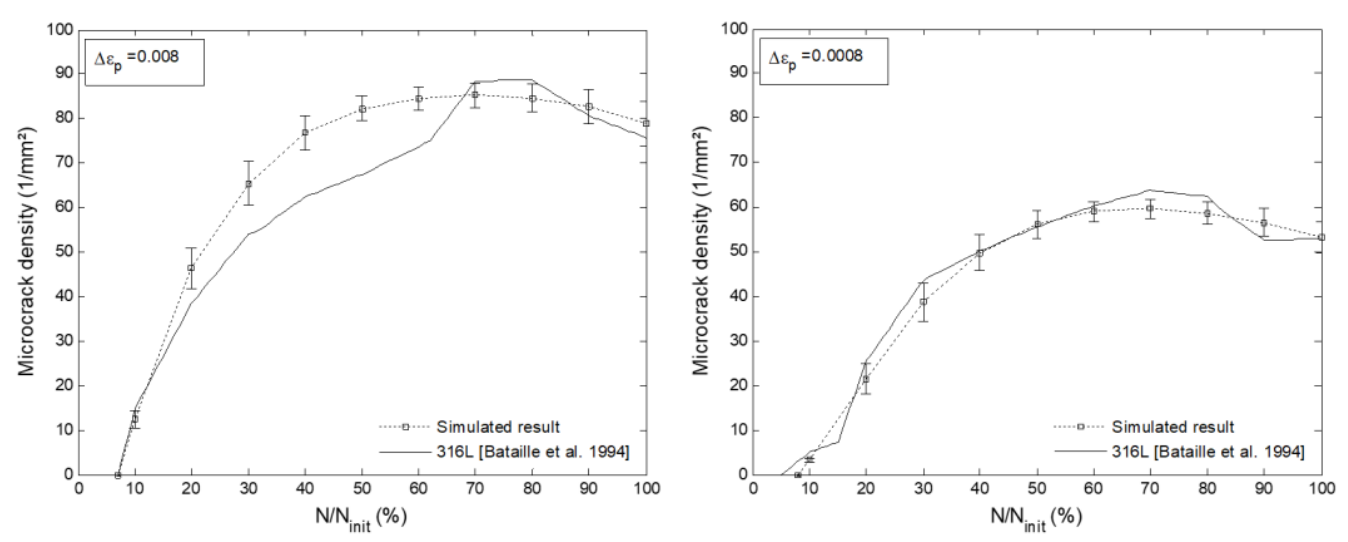

Figure 2. Microcrack density evolution. $\Delta \varepsilon_{\mathrm{p}}=8 \cdot 10^{-4}$

The number of cycles corresponding to the dominant crack formation is, in turn, in good accordance with the experimental data (Bataille et al. 1994) (Fig. 3). However, the analysis of the cracking process, for different plastic strain ranges, clearly indicates that the coalescence phenomenon contributes to the development of microcracks, and takes part in the formation of most dominant cracks. Thus, coalescence seems to be in large part responsible for the dispersion observed in the CIL.

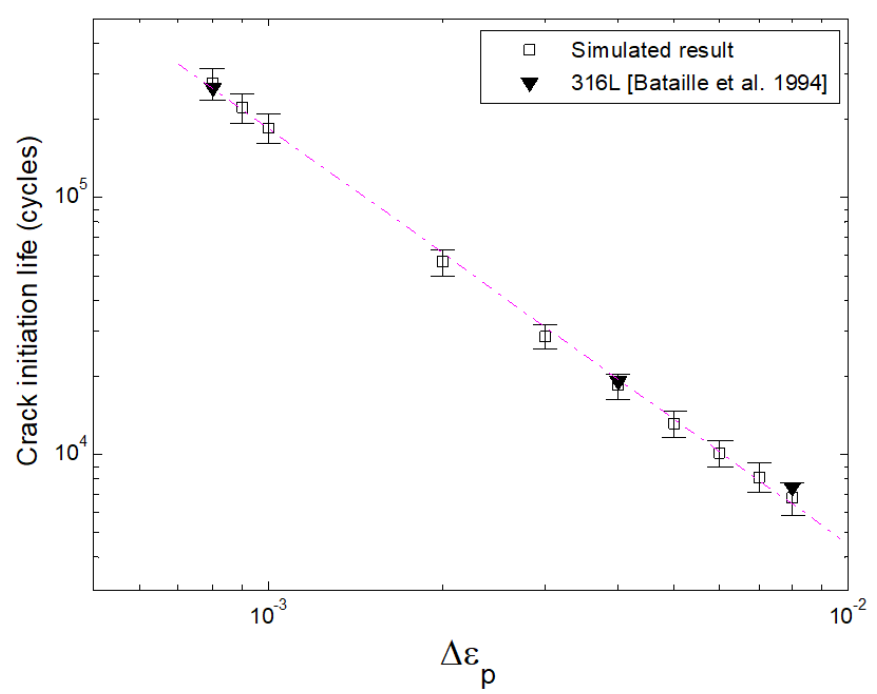

Figure 3. Evolution of the crack initiation life vs. plastic strain range $\left(\Delta \varepsilon_{p}\right)$

For each plastic strain range, four statistical distributions are considered for the CIL: normal, lognormal, Weibull and exponential. The chi-square and the Anderson-Darling tests are used to evaluate the goodness-of-fit. The statistical analysis of the obtained results indicates that the CIL follows the lognormal distribution (Fig. 4a), which is commonly used for fatigue lifetime description. A similar result is obtained for the study of crack initiation of an aluminium alloy under constant-amplitude loading (Min et al. 1996). However, for $\Delta \varepsilon_{p}$ between $8.10^{-4}$ and $3.10^{-3}$, the analysis shows that the normal probability density function is the one that best fits the computed results (Fig. 4b). 

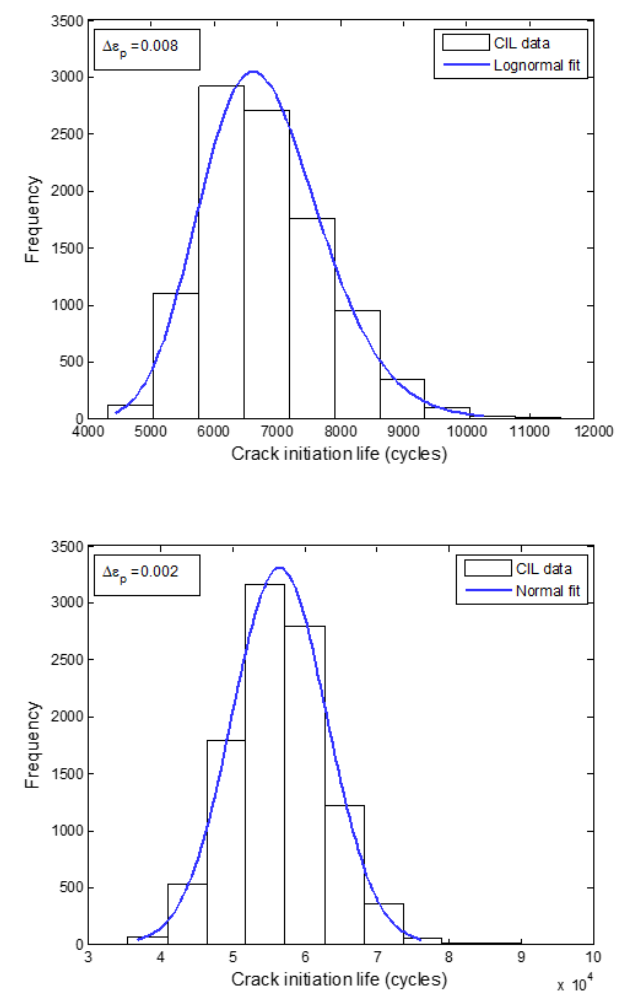

(a)
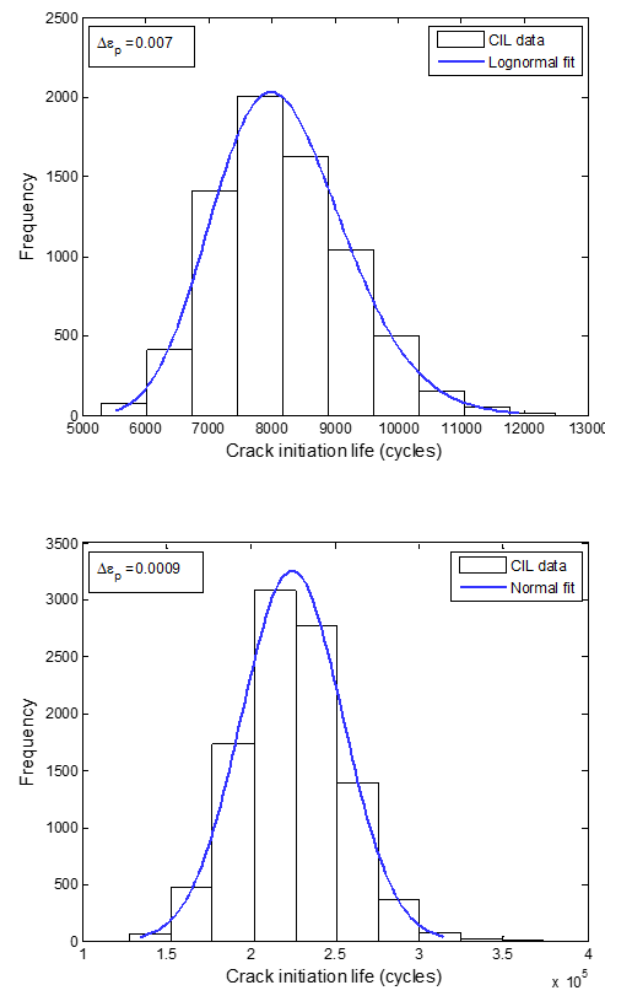

Figure 4. Statistical distribution of the simulated crack initiation life. (a) lognormal fit; (b) normal fit

Fig. 5 presents the evolution of the coefficient of variation $(\mathrm{Cv})$ of the CIL as a function of $\Delta \varepsilon_{p} . \mathrm{Cv}$ is defined as the standard deviation divided by the mean value, and it is used as a measure of the scatter obtained in the simulated results. The values of $\mathrm{Cv}$ show a slight increase for the highest ranges of plastic strain, which can be attributed to microcracks coalescence. Indeed, this phenomenon introduces the notion of hazard in the formation of the dominant crack, particularly when microcrack density becomes high (Liu et al. 2019).

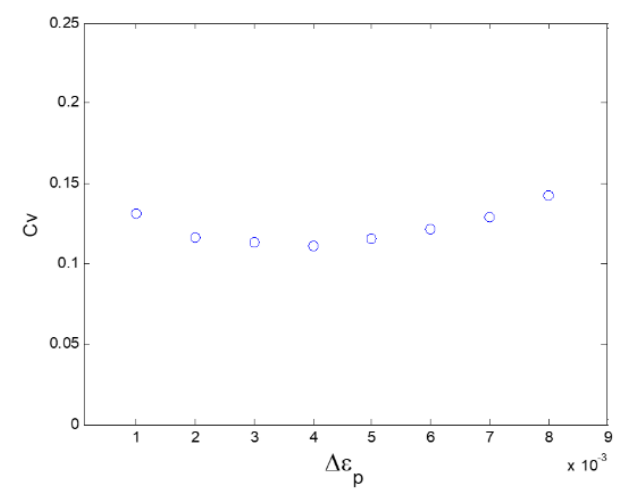

Figure 5. Coefficient of variation $(\mathrm{Cv})$ vs. plastic strain range $\left(\Delta \varepsilon_{p}\right)$. 


\section{Conclusion}

The stochastic model proposed in the present study can be successfully used for fatigue crack initiation life assessment, where the dominant crack results from the development of multiple microcracks. The effect of grain boundaries and the interaction of microcracks between themes, during their growth, must be taken into account as they significantly affect the formation of the dominant crack.

The obtained results reveal that the coalescence phenomenon contributes to the formation of most of the dominant cracks, and is largely responsible for the observed dispersion of the CIL. Furthermore, the description of the CIL with a typical distribution law without considering the amplitude of the applied plastic strain, as usually proceeded, may not be convenient. According to $\Delta \varepsilon_{\mathrm{p}}$, the CIL can be described by a lognormal distribution for high $\Delta \varepsilon_{\mathrm{p}}$, while for low $\Delta \varepsilon_{\mathrm{p}}$, i.e. $\Delta \varepsilon_{\mathrm{p}}<3.10^{-3}$ in the case of the $316 \mathrm{~L}$, a normal distribution is more appropriate.

\section{Reference}

Bataille A, Magnin T (1994). Surface damage accumulation in low-cycle fatigue: physical analysis and numerical modelling, Acta Met. mater., 42(11), 3817-3825.

Bertolino G, Bilger N, Crépin J (2007). Modeling microstructures and microstructural effects on macroscopic and intragranular mechanical behavior, Comput. Mater. Sci., 40, 408-416.

Brechet Y, Magnin T, Sornette D (1992). The coffin-manson law as a consequence of the statistical nature of the lcf surface damage, Acta Met. mater., 40(9), 2281-2287.

Carstensen JV, Magnin T (2001). Characterisation and quantification of multiple crack growth during low cycle fatigue, Int. J. Fatigue, 23, 195-200.

Deng GJ, Tu ST, Zhang XC, Wang QQ, Qin CH (2015). Grain size effect on the small fatigue crack initiation and growth mechanisms of nickel-based superalloy GH4169, Eng. Fract. Mech., 134, 433-450.

Gall K, Biallas G, Maier HJ, Horstemeyer MF, McDowell DL (2005). Environmentally influenced microstructurally small fatigue crack growth in cast magnesium, Mater. Sci. Eng. A, 396(1-2), 143-154.

Golden PJ, Whitney-Rawls A, Jha SK, Porter WJ, Buchanan D, Prasad K, Chandravanshi V, Kumar V, John R (2019). Probabilistic prediction of minimum fatigue life behaviour in $\alpha+$ $\beta$ titanium alloys. Fatigue and Fracture of Engineering Materials and Structures, 42(3), 674-685.

Hong Y, Zheng L, Qiao Y (2002). Simulations and experiments of stochastic characteristics for collective short fatigue cracks in steels, Fatigue Fract Engng Mater Struct, 25, 459-466.

Ignatovich SR, Kucher AG, Yakushenko AS, Bashta AV (2005). Modeling of coalescence of dispersed surface cracks. Part 2. Simulation model for multiple fracture, Strength Mater., 37(1), 79-85.

Jiŝa D, Liŝkutín P, Kruml T, Polák J (2010). Small fatigue crack growth in aluminium alloy ENAW 6082/T6, Int. J. Fatigue, 32, 1913-1920.

Lankford J (1985). The Influence of Microstructure on the Growth of Small Fatigue Cracks, Fatigue Fract. Eng. Mater. Struct., 8(2), 161-175.

Liu T, Shi X, Zhang J, Fei B (2019). Crack initiation and propagation of 30CrMnSiA steel under uniaxial and multiaxial cyclic loading, Int. J. Fatigue, 122, 240-255.

Lukáš P, Kunz L (2003). Small cracks - Nucleation, growth and implication to fatigue life, Int. J. Fatigue, 25, 855-862.

Magnin T, Ramade C, Lepinoux J, Kubin LP (1989). Low-cycle fatigue damage mechanisms of F.c.c. and B.c.c. polycrystals: Homologous behaviour?, Mater. Sci. Eng. A, 118, 41-51. 
Malésys N, Vincent L, Hild F (2009). A probabilistic model to predict the formation and propagation of crack networks in thermal fatigue, Int. J. Fatigue, 31(3), 565-574.

Mazánová V, Polák J (2018). Initiation and growth of short fatigue cracks in austenitic Sanicro 25 steel, Fatigue Fract. Engng Mater. Struct., 41(7), 1529-1545.

Miller KJ (1987). The behaviour of short fatigue cracks and part II - a general summary, Fatigue Fract Engng Mater Struct, 10(2), 93-113.

Min L, Qing S, Qing-xiong Y (1996). Large sample size experimental investigation on the statistical nature of fatigue crack initiation and growth, Int. J. Fatigue, 18(2), 87-94.

Plumtree A, O'connor BPD (1991). Influence of microstructural barriers on short fatigue crack growth, Fatigue Fract Engng Mater Struct, 14(2/3), 171-184.

Provan JW, Zhai ZH (1991). Fatigue crack initiation and stage-I propagation in polycrystalline materials. II: Modelling, Int. J. Fatigue, 13(2), 110-116.

Qiao Y, Chakravarthula SS (2005). Effects of randomness of grain boundary resistance on fatigue initiation life, Int. J. Fatigue, 27, 1251-1254.

Varvani-Farahani A, Topper TH, Plumtree A (1996). Confocal scanning laser microscopy measurements of the growth and morphology of microstructurally short fatigue cracks in $\mathrm{Al}$ 2024-T351 alloy, Fatigue Fract. Engng Mater. Struct., 19(9), 1153-1159.

Vašek A, Polak J (1991). Low Cycle Fatigue Damage Accumulation in Armco-Iron, Fatigue Fract. Engng Mater. Struct., 14(2-3), 193-204.

$\mathrm{Xu} \mathrm{L}$, Wang Q, Zhou M (2018). Micro-crack initiation and propagation in a high strength aluminum alloy during very high cycle fatigue, Mater. Sci. Eng. A, 715(7), 404-413.

Zhixue W (2001). Short fatigue crack parameters describing the lifetime of unnotched steel specimens, Int. J. Fatigue, 23(4), 363-369.

Zhu SP, Foletti S, Beretta S (2018). Evaluation of size effect on strain-controlled fatigue behavior of a quench and tempered rotor steel: Experimental and numerical study, Mater. Sci. Eng. A, $735,423-435$. 